\title{
MENINGORRADICULOMIELOPATIA ESQUISTOSSOMÓTICA
}

\author{
Milberto ScafF * \\ DANIELE RIVA ** \\ A. SPINA-França ***
}

As localizações nervosas da esquistossomose são bastante raras, mesmo nos países em que a endemia atinge altas percentagem da população. Dentro dessa raridade pode-se acompanhar, pela literatura, o número crescente de publicações sôbre o assunto, o que mostra o interêsse que êle desperta em função de ser mais freqüente o diagnóstico em vida.

A essa raridade da neuro-esquistossomose clìnicamente manifesta, contrapõe-se a grande freqüència da infestação assintomática do sistema nervoso central (SNC). As investigações de Gelfand ${ }^{6}$ são esclarecedores a êsse respeito. Este pesquisador submeteu porções de tronco cerebral, de cerebelo e de hemisférios cerebrais à digestão pela potassa cáustica a $10 \%$ examinando, a seguir, o macerado à procura de ovos; dos 50 casos de esquistossomose comprovada (sem manifestações neurológicas) 28 tinham ovos em mais do que uma das partes examinadas. Deve ser destacado que todos os ovos encontrados foram de Schistosoma haematobium, embora 21 dos 50 pacientes tivessem uma infestação conjunta pelo Schistosoma mansoni. Este fato mostra que os ovos do Schistosoma mansoni não alcançam o encéfalo com tanta facilidade quanto os do Schistosoma haematobium. Gelfand estudou, pelo mesmo método, as medulas de 25 pacientes, encontrando ovos de Schistosoma haematobium em um, assintomático sob o ponto de vista neurológico. A incidência de comprometimento assintomático na medula é, portanto, muito menor que no encéfalo, talvez em virtude do maior volume dêste em relação àquela.

Dentro desta perspectiva Spina-França e Amato ${ }^{12}$ estudaram o líquido cefalorraqueano (LCR) em 42 casos de esquistossomose neurològicamente assintomáticos. Esses autores não encontraram alterações significativas no LCR dêsses pacientes, mostrando que os achados anátomo-patológicos de Gelfand ${ }^{6}$ não têm um paralelo liquórico; entretanto deve ser destacado que as espécies de Schistosoma são diferentes nêsses dois estudos, tendo o Schistosoma mansoni tropismo reduzido pelo SNC, quando comparado com o Schistosoma haematobium.

Trabalho da Clinica Neurológica do Hospital das Clínicas da Faculdade de Medicina da Universidade de São Paulo (Prof. H. M. Canelas) apresentado no IV Congresso Brasileiro de Neurologia (Pôrto Alegre, Julho de 1970): * Médico-assistente; ** Instrutor de ensino; *** Docente. 
Analisando os casos de neuro-esquistossomose publicados no Brasil, notase que a localização cerebral é bastante rara $^{8}$ e que, na grande maioria, trata-se de formas de comprometimento medular. Excepcionais neste sentido são os casos registrados por Oliveira e Alencar ${ }^{9}$ e por Couto ${ }^{2}$. No caso publicado pelos primeiros autores a sintomatologia se iniciara com sinais de comprometimento mielorradicular seguidos, após 6 meses, por uma evolução ascendente tipo Landry, com fenômenos bulbares e morte. $\mathrm{O}$ caso de Couto $^{2}$ apresentava um quadro clínico de esclerose lateral amiotrófica, inclusive com sinais bulbares.

De maneira geral, a mielopatia esquistosscmótica pode adotar a forma mielítica ou a forma pseudotumoral com bloqueio do canal raqueano. O primeiro caso publicado no Brasil por Gama e Sá ${ }^{4}$ apresentava quadro de compressão medular; durante o ato cirúrgico foi retirada formação tumoral constituída de numerosos granulomas contendo ovos de Schistosoma mansoni. A forma mielítica, geralmente com as características de síndrome medular transversa de evolução aguda ou sub-aguda, tem evolução mais grave do que a forma pseudotumoral ${ }^{10}$, talvez em virtude da dificuldade diagnóstica nestas formas em que não há indicação cirúrgica.

O diagnóstico, em ambas as formas apresenta grandes dificuldades, existindo porém elementos que podem orientá-lo, tais como eosinofilia sangüínea, eosinofilorraquia, concomitância de um quadro de esquistossomose hepatoesplênica ou intestinal e a procedência de áreas endêmicas. Segundo Oliveira e Alencar ${ }^{9}$ a intensidade e a duração dos sintomas radiculares seriam também uma pista para o diagnóstico. O melhor elemento, porém, é a reação de fixação de complemento para esquistossomose no LCR cuja utilização foi registrada pela primeira vez na literatura por Canelas, Aidar e $\operatorname{Campos}^{1} \mathrm{e}$ destacada por Vieira da Silva ${ }^{13}$.

E objeto desta publicação analisar os achados referentes a dois novos casos, nos quais o diagnóstico foi baseado em dados imunobiológicos.

\section{O B S E R V A C O E S}

Caso 1 - J.C.S., 31 anos, sexo masculino, branco, lavrador, procedente do Estado de Alagôas (Registro HC 839.880), internado em 25-julho-1967. Cêrca de 5 meses antes da internação, o paciente começou a sentir dormência ao nivel do pé direito e sensação de fraqueza no pé esquerdo. Os sintomas foram-se estendendo até atingir a cicatriz umbelical. Embora continuasse trabalinando, o paciente caía com frequêencia. $\mathrm{Na}$ ocasião da internação queixava-se de dormência no membro inferior direito e na metade inferior direita do abdome, bem como fraqueza no membro inferior esquerdo. Há dois meses vinha apresentando incontinência urinária e fecal. Relata o paciente que tomava banho em "lagoas de coceira" e que dois irmãos faleceram acometidos por esquistossomose. Exame clinico sem anormalidades. Exame neurológico - Paraparesia crural sendo o deficit motor mais acentuado à esquerda. Marcha parética. Reflexos patelar e aquiliano exaltados à esquerda e vivos à direita; sinal de Babinski presente à esquerda. Anestesia térmica e dolorosa no membro inferior direito e no quadrante inferior direito do abdome. Do lado esquerdo, hipoestesia térmica e dolorosa com distribuição semelhante à do lado direito. Sensibilidade táctil, conservada. Sensibilidade artrestésica conservada. Sensibilidade vibratória: hipopalestesia nos hálux. Exames complementares - Exa- 
me parasitológico de fezes: presença de ovos de Schistosoma mansoni. Reação de tmunofiuorescencia para schistosoma mansoni no sôro positiva $(+++)$ e no LCR positiva $(++)$. Proteinograma do sôro sangüineo (eletroforese em papel): albumina 3,0 ; globulinas: alfa-1 0,4 ; alfa-2 1,0; beta 1,3; gama 2,1 (resultados em $\mathrm{g} / 100 \mathrm{ml}$ ). Perimieiografia com lipiodol normal. $L C R$ (ver quadro 1). Tratamento - $O$ paciente foi medicado com Ambilhar durante 7 dias, tendo melhorado. Evolução Por ocasião da alta hospitalar (11-dezembro-1967), apresentava paresia do membro inferior esquerdo, hipoestesia térmica e dolorosa no membro inferior direito. $O$ sinal de Babinski desaparecera.

Caso 2 - A.N.B., 17 anos, sexo masculino, branco, lavrador, procedente do Estado da Bahia (Registro HC 34.902), internado em 7-abril-1969. Um mês antes da internação, de modo brusco, o paciente começou a ter dores epigástricas violentas, acompanhadas de vómitos. Poucas horas após já não conseguia mover os membros inferiores. Desde o inicio ocorreu incontinência urinária e fecal. Exame clínico sem anormalidades; figado e baço não palpáveis. Exame neurológico Paraparesia crural flácida, com arreflexia superficial e profunda. Anestesia global até o nivel do sexto segmento toráxico; hipoestesia também global do sexto ao quarto segmentos toráxicos. Incontinência urinária e fecal. Exames complementares - Reaçōes sorologicas para sífilis negativas. Reação para blastomicose e para criptococose no LCR e no sôro negativas. Reação de fixação de complemento para Schistosoma mansoni * (10-6-1969) no LCR positiva (titulo 31.6); repetida (17-11-1969) foi negativa no LCR e positiva no sôro (título 6,7). Reação intradérmica com esquistossomina positiva. Proteinograma do sôro sangüineo (eletroforese em papel): albumina 2,69; globulinas alfa-1 0,68 ; alfa-2 1,74; beta 1,27; gama 2,12 (resultados em g/100 ml). Perimielografia com lipiodol normal. LCR (ver quadro 1). Tratamento - O paciente foi medicado com Hicantone $(2,5 \mathrm{mg} / \mathrm{kg}$ de pêso), mediante uma única dose intramuscular. Evolução - Os primeiros sinais de liberação piramidal começaram a aparecer 5 meses após o início do quadro.

\section{O M E N T A R O S}

Quanto à patogenia da neuro-esquistossomose em geral e das formas medulares em particular há divergências de opiniões, especialmente no tocante ao caminho seguido pelos vermes e seus ovos até atingir o parênquima nervoso. Alguns autores acreditam que a disseminação se faça por via arterial; assim Espin ${ }^{3}$ admite que o verme migre dos ramos intra-hepáticos da veia porta, através de anastomoses arteriovenosas, até ramos da artéria hepática, atingindo a aorta e indo, daí, até uma artéria espinal anterior, aonde seria realizada a postura. Vários argumentos falam contra esta hipótese: em primeiro lugar, seria difícil compreender a migração de um verme adulto através de microfístulas nas quais o fluxo seria sempre na direção artéria-veia, em virtude do grande gradiente de pressão aí existente. Por outro lado, estudos histopatológicos mostram que a reação ao ôvo se faz invariàvelmente a partir de uma vênula, como se vê claramente quando o material é estudado em cortes seriados. Segundo Potenza ${ }^{11}$ a disseminação se faria por via arterial, após a passagem dos ovos da veia porta para o sistema cava e depois do franqueamento das anastomoses arteriovenosas pulmonares. Esta maneira de disseminação difìcilmente chegaria a explicar a deposição maciça de ovos

* Os autores agradecem ao Dr. J. Pellegrino (Instituto Nacional de Endemias Rurais, Belo Horizonte, MG) pela feitura destas reações. 


\begin{tabular}{|c|c|c|c|c|c|c|c|c|c|c|c|c|c|c|c|}
\hline \multirow{3}{*}{ Caso } & \multirow{3}{*}{ Data } & \multicolumn{5}{|c|}{ Citologia } & \multirow{3}{*}{$\begin{array}{l}\text { Glicose } \\
(\mathrm{mg} / 100 \\
\mathrm{ml})\end{array}$} & \multirow{3}{*}{$\begin{array}{c}\text { Proteinas } \\
\text { totais } \\
(\mathrm{mg} / 100 \\
\mathrm{ml})\end{array}$} & \multirow{3}{*}{$\begin{array}{c}\text { Pré- } \\
\text { albumina }\end{array}$} & \multicolumn{2}{|c|}{ Fraco es } & \multicolumn{2}{|c|}{ protê ic as } & \multicolumn{2}{|l|}{$(\%)$} \\
\hline & & \multirow{2}{*}{$\begin{array}{l}\text { Global } \\
\left(\mathrm{mm}^{3}\right)\end{array}$} & \multicolumn{2}{|c|}{ Específica } & \multirow{2}{*}{$\begin{array}{l}(\%) \\
\mathrm{Ne}\end{array}$} & \multirow{2}{*}{ Eo } & & & & & \multicolumn{5}{|c|}{ G lobulinas } \\
\hline & & & $\mathrm{L} \mathbf{i}$ & Mo & & & & & & na & alfa-1 & alfa-2 & beta & $\operatorname{tau}$ & gama \\
\hline \multirow[t]{4}{*}{1} & $12-6$ & 7,3 & 85 & 12 & 2 & 1 & 66 & 57 & & & & & & & \\
\hline & $9-8$ & 14,0 & 88 & 12 & & & 52 & 61 & 0 & 50,6 & 3,8 & 9,4 & 11,8 & 4,2 & 20,2 \\
\hline & $31-8$ & 17,0 & 75 & 15 & 10 & & 48 & 101 & & & & & & & \\
\hline & $6-11$ & 3,3 & & & & $*$ & 60 & 79 & 5,6 & 52,6 & 5,1 & 8,1 & 12,6 & 3,2 & 12,4 \\
\hline \multirow[t]{3}{*}{2} & $7-4$ & 120,0 & 100 & & & $*$ & 40 & 94 & 0,5 & 31,3 & 7,2 & 10,3 & 10,7 & & 40,0 \\
\hline & $6-8$ & 23,0 & 100 & & & & 44 & 68 & & & & & & & \\
\hline & $17-9$ & 0 & & & & & 68 & 59 & & & & & & & \\
\hline
\end{tabular}

Quadro 1 - Exames de liquido cef́alorraqueano nos dois casos estudados. Punções lombares. Provas manométricas de Queckenstedt-Stookey normais. Legenda: Li = linfócitos; Mo = monócitos; Ne = polinucleares neutrófilos; Eo = células eosinófilas; ${ }^{*}$ granulações eosinófilas livres. 
em segmentos circunscritos do sistema nervoso, com formação de massas granulomatosas pseudotumorais.

Atualmente a maioria dos autores acredita que os vermes alcancem o tecido nervoso através do plexo venoso de Batson ${ }^{10}$. Éste plexo, desprovido de válvulas, teria comunicação não só com os sistemas venosos (porta, cava e azigos) mas também com os grandes seios e veias intracranianos, o que o torna especialmente apto a desempenhar importante papel, no afluxo ao SNC, de células tumorais, bactérias e macroparasitas. A migração dos vermes do seu habitat natural seria facilitada pela hipertensão portal existente em numerosos pacientes e pelas posições e atos que aumentam a pressão intra-abdominal e diminuem a pressão no espaço epidural (flexão da coluna, defecação) ${ }^{5}$. Nestas condições os vermes seriam como que aspirados para os sistemas venosos intra-raqueanos e colonizariam um vênula, onde seria realizada a postura. Isto explica o encontro de ovos em fileiras, fato destacado por Couto ${ }^{2}$.

O nosso primeiro paciente (J.C.S.) apresentava uma síndrome medular pouco habitual na literatura sôbre mielopatias esquistossomóticas, pois tendia francamente para o tipo Brown-Séquard. No restante, vários elementos falavam a favor da etiologia em questão, destacando-se a procedência e o fato de dois irmãos terem contraído a moléstia. Porém, o diagnóstico de neuroesquistossomose neste caso só pode ser de probabilidade: a reação de Farley foi positiva no LCR, mas seu título foi menor que o titulo no sangue. Este fato levanta dúvidas quanto à possibilidade de os anticorpos fixadores de complemento terem passado do sangue para os espaços liquóricos.

A eletroforese das proteínas do LCR mostrou aumento da globulina gama em ambos os casos; o pêso dêste achado precisa ser consolidado por futuros estudos sôbre as proteinas do LCR, nas mielopatias provocadas pelo Schistosoma mansoni.

Nosso segundo paciente (A.N.B.), procedente de área endêmica apresentou uma sindrome medular transversa de instalação abrupta. Analisando esta evolução sob forma de icto, merecem ser lembrados os achados anátomopatológicos de Maciel, Coelho e Abath ${ }^{7}$ : o exame da medula do paciente acompanhado por êstes autores mostrou várias áreas de amolecimento, em relação com exuberantes fenômenos arteríticos.

É nossa impressão que estas síndromes transversas fulminantes têm como substrato reações vascularíticas de patogenia imunitária desencadeadas pela presença dos ovos na intimidade do tecido nervoso. No caso que relatamos o quadro liquórico era altamente sugestivo de neuro-esquistossomose. A reação de fixação de complemento positiva em título alto veio confirmar o diagnóstico.

Um elemento adicional de valor para o diagnóstico é a boa resposta à terapêutica; nos dois casos aqui relatados houve sensivel melhora tanto do quadro liquórico como, embora em menor grau, do quadro clínico. 
Estudo clínico e laboratorial de dois casos de meningorradiculomielopatia esquistossomótica. Considerações são feitas sôbre a fisiopatologia e manifestações neurológicas desta parasitose. A positividade das reações imunológicas para Schistosoma mansoni no líquido cefalorraqueano e as melhoras obtidas mediante terapêutica adequada foram valorizadas para o diagnóstico.

\section{S U M M A R Y}

Schistosomal meningoradiculomyelopathy: report of two cases

The clinical and laboratory findings in two cases of shistosomal meningoradiculomyelopathy due to Schistosoma mansoni are reported. In case 1 the onset and the evolution of the disease assumed a progressive character; the neurologic examination showed a picture similar to the Brown-Sequard syndrome. In case 2 the onset was acute and the neurologic examination has shown a complete transverse myelopathy syndrome at the middle toracic level.

The cerebrospinal fluid examination showed in the two cases: cells counts increased, normal or low sugar and increased protein. The study of CSF protein profile showed increased gamma-globulin in the two cases. The immunological reactions in the blood and CSF were positive in the two cases. Good results were obtained with especific therapy.

\section{R E F E R E N C I A S}

1. CANElAS, H. M.; AIDAR, O. \& CAMPOS, E. P. - Esquistossomose com lesões meningo-radiculo-medulares. Arq. Neuro-Psiquiat. (São Paulo) 9:48, 1951.

2. COUto, B. - Esquistossomose medular. Tese. Of. Graf. Univ. Brasil, Rio de Janeiro, 1960.

3. ESPIN, J. Mielitis producida por huevos de Schistosoma mansoni. Rev. Policl. (Caracas) 10:245, 1941.

4. GAMA, C. \& SA, J. M. M. - Esquistossomose medular. Arq. Neuro-Psiquiat. (São Paulo) 3:334, 1945.

5. GAMA, C. - Compression granuloma of spinal cord caused by Schistosoma mansoni ova. Report of a case. J. Int. Coll. Surg. 19:665, 1953.

6. Gelfand, M. - Schistosomiasis in South Central Africa. Post. graduate Press, Capetown, 1950.

7. MACIEL, Z.; COELHO, B. \& ABATH, G. - Mielite esquistossomótica (Schistosoma mansoni). Estudo clínico-patológico. An. Fac. Med. Univ. Recife 14:207, 1954.

8. MATTOSINHO-FRANÇA, L. C.; MELARAGNO Filho, R. \& TENUTO, R. A. - Comprometimento cerebral na esquistossomose mansônica. Rev. paul. Med. $67: 223,1965$.

9. OlIVEIRA, C. \& ALENCAR, A. - Esquistossomose da medula. Apresentação de um caso, revisāo da literatura, físiopatologia e clínica. J. brasil. Neurol. 16:91, 1964 . 
10. PIQUeT-CARNEIRO, A.; ALVARIZ, F. R. \& SERRA, J. P. - Mielite esquistossomótica. O Hospital (Rio de Janeiro) 47:237, 1955.

11. POTENZA, L. - Localizaciones aberrantes del Schistosoma mansoni. G.E.N. (Caracas) 10:525, 1955.

12. SPINA-FRANCA, A. \& AMATO Neto, V. - O liquido cefalorraquidiano na esquistossomose mansoni. Rev. paul. Med. 46:274, 1955.

13. VIEIRA DA SILVA, L. L. - Contribuição ao estudo da neuroesquistossomose. Bol. Cent. Est. Hosp. Serv. Est. (Rio de Janeiro) 15:95, 1963.

Clínica Neurológica - Faculdade de Medicina, Universidade de São Paulo Caixa Postal 3461 - São Paulo, SP - Brasil. 